\title{
Interview with Stephen Hunt
}

\author{
Entrevista com Stephen Hunt
}

José Duarte (FLUL/CEAUL)

Ana Rita Martins (FLUL/CEAUL)

We had the opportunity to interview Stephen Hunt for this special issue of Redisco. Stephen Hunt is an English fantasy, science fiction and thriller/crime author. His best-known works, the Jackelian series of fantasy novels, originally appeared in the UK, Canada, Australia, and New Zealand, through the Voyager imprint of HarperCollins and these novels are now published all around the world. He has a major new fantasy series - the Far-called Sequence - the first novel of which has now come out in 2014, called In Dark Service and published by Gollancz (an imprint of Orion Publishing and Hachette Livre). Website: http://stephenhunt.net. 
Could you describe who is Stephen Hunt the author and Stephen Hunt the man?

I am currently a full time author and have been since 2007. Before that I worked as an editor and publisher for a variety of publishers, usually helping them set up and run their first Web sites. Past employers include the Financial Times at ft.com and the science journal Nature at Nature.com. I also set up the first online science fiction magazine just for fun at www.SFcrowsnest.org.uk.

\section{How did you become interested in writing Fantasy? Did you always read Fantasy fiction?}

I have always been a big reader of fantasy, science fiction and horror, aided, no doubt, by my father, who is also a big reader and fan of the genre. I grew up surrounded by a library of all the classics from the 1930s up ... E.E. Doc. Smith, Arthur C. Clarke, Jack Williamson, Michael Moorcock, and later on authors like William Gibson. My father became a fan when the armament ships sent to the UK by the USA during world war two contained copies of early Sci-fi magazines like Amazing Stories as ballast, and the magazines were given free to school kids who would wait on the docks for them.

What is the importance the city plays in your novels, particularly Victorian London?

Victorian London was the template for the City of Middlesteel in my six Jackelian novels. A lot of the things that people believe I invented, such as the Atmospheric transport system, were actually based on real historical prototypes that never went into full production. It is easy to plunder real history for fiction. Nobody ever believes it could have been true. 
What are your real historical and cultural inspirations for developing the Jackelian universe?

A lot of the Jackelian books were structured as my answer to what the real character of the British people is like. J. R. R. Tolkien did this for his time and came up with the answer of the Shire ... hobbits and a lost rural idyllic. My answer was rebellious football hooligans who would like to have a punch up on the floor of Parliament in between torturing their Royal Family like a put upon hound.

How do you perceive your Jackelian Series within the Fantasy genre? Do you agree with the term Flintlock Fantasy, which was essentially coined after For the Crown and the Dragon?

I am fairly happy to go along with the steampunk label for the Jackelian books. Before The Court of the Air nobody had really heard of the term apart from a few fans of The Difference Engine. When the publishers saw the success of my first book, everyone seemed to jump on the bandwagon, and now you have a whole legion of cosplayers and device designing modders who do not really read the books, but who bring massive creativity to the genre.

Can you elaborate more on the entities that appear in your novels? Such as Steampunk bodies (like Steammen) and other characters with technological and magical powers?

The steammen were a race of intelligent self-designing machines I wanted to create just to give them a moral and religious system superior to the humans in the books. There was a lot of Zen and Tibet in their culture, too. In many ways they are the nicest and most gentle characters in my novels. 
Technology and magic often don't go together so how do you manage to create a balance between these two?

The Jackelian books are set millions of years in the future after the rise and fall of countless advanced civilisations. Most of what is perceived as magic is actually the byproduct of ancient higher societies and various imported alien races attempts at genetic engineering and similar.

Recently the academia has been paying closer attention to Fantasy and Science Fiction genres (this particular Redisco's number being an example of that), which some authors have welcomed while others have criticized. How do you think academic studies can contribute or not to the widespread of the genre?

I recognise that historically fantasy and science fiction have been looked down on as not serious literature. I think that where we are today is the realisation that fantasy is the mother of all forms of literature ... from Homer to the Egil's saga of Iceland. All genres from crime mystery through to pretentious contemporary fiction are the bastard offspring of fantasy ... even science fiction is just a minor offspring of the fantasy mother lode. Academia is intelligent enough to know it's own history in this regard, even if critics fail the test.

With so many Fantasy films being adaptations of novels is there any chance the Jackelian Series will be on cinema or eventually television?

There hasn't been any movement on movie news for a long while. After The Court of the Air was voted the best book to be made into a film by the Committee of the Berlianale film festival, there was a lot of interest from Hollywood, but I think the publisher HarperCollins, who also do the Narnia and Lord of the Rings films from bookto-movie, were asking for a small fortune for the rights, and the film deal eventually evapourated. The Japanese translation of the books are very popular, so who knows, maybe an anime series one day? 


\section{Could you unveil a little bit of a future project?}

Most the demand from my fans has been for more books set in my space opera series of science fiction novels, the Sliding Void books, so I will certainly be writing more of them. I will also be working with thousands of secondary schools in the UK, Canada, Australia, Ireland, New Zealand and the USA via my www.theauthorsapprentice.co.uk platform again. Last year I wrote the vampire novel Hell Sent in collaboration with English speaking students around the world, and that was great fun. It also enables me to help with building a passion for literacy among school age students. It's nice to use the Internet for something other than sharing cat video memes and Selfies for a change. I have promised my pupils that in 2017 I will write the seventh Jackelian novel, Mission to Mightadore, on this literary-focused social network, collaborating with them.

Recebido em 12/12/2016

Aceito em 15/02/2017. 